Gut and Liver, Vol. 12, No. 5, September 2018, pp. 483-496

\title{
Diagnostic Endoscopic Ultrasound: Technique, Current Status and Future Directions
}

\author{
Tiing Leong Ang ${ }^{1}$, Andrew Boon Eu Kwek ${ }^{1}$, and Lai Mun Wang ${ }^{2}$ \\ ${ }^{1}$ Department of Gastroenterology and Hepatology and ${ }^{2}$ Section of Histopathology, Department of Laboratory Medicine, Changi General \\ Hospital, Singapore
}

Endoscopic ultrasound (EUS) is now well established as an important tool in clinical practice. From purely diagnostic imaging, it has progressed to include tissue acquisition, which provided the basis for therapeutic procedures. Even as interventional EUS developed, there has been ongoing progress in EUS diagnostic capabilities due to improved imaging systems, better needles for tissue acquisition and development of enhanced imaging functions such as contrast harmonic EUS (CHEUS) and EUS elastography. EUS is well established for differentiation of subepithelial lesions, for T-staging of luminal gastrointestinal and pancreaticobiliary malignancies, for differentiation of benign pancreaticobiliary disorders and for diagnostic tissue acquisition, which can be achieved by EUS-guided fine needle aspiration or by EUS-guided fine needle biopsy using dedicated biopsy needles. This review briefly describes the technique of performing EUS and then discusses its clinical utility in terms of gastrointestinal cancer staging, the evaluation of pancreaticobiliary disorders and tissue acquisition. Enhanced imaging techniques such as CHEUS and EUS elastography are briefly reviewed. (Gut Liver 2018;12:483-496)

Key Words: Endosonography; Neoplasm staging; Biopsy, fine-needle

\section{INTRODUCTION}

Endoscopic ultrasound (EUS) is now well established as an important tool in clinical practice. From purely diagnostic imaging, it has progressed to include tissue acquisition which provided the basis for therapeutic procedures. Even as interventional EUS developed, there has been ongoing progress in EUS diagnostic capabilities due to improved imaging systems, bet- ter needles for tissue acquisition and development of enhanced imaging functions such as contrast harmonic EUS (CHEUS) and EUS elastography. This review briefly describes the technique of performing EUS and then discusses its clinical utility in terms of gastrointestinal cancer staging, the evaluation of pancreaticobiliary disorders and tissue acquisition. Enhanced imaging techniques such as CHEUS and EUS elastography are briefly reviewed.

\section{TECHNIQUE OF EUS EXAMINATION}

EUS can be performed using either radial or linear echoendoscopes. The former provides imaging with a $360^{\circ}$ view similar to computer tomography (CT), while the latter provide a narrower sector longitudinal imaging, which is important to allow real time tracking of a puncture needle, crucial for EUS-guided interventions. The radial echoendoscope is generally used for assessment of the gut wall such as T-staging, as it provides a better overview. The linear echoendoscope can achieve a similar diagnostic performance level as the radial echoendoscope for pancreaticobiliary imaging. ${ }^{1-4}$ Miniature probes (mini-probes) are also available and can simply be inserted through the working channel of an endoscope for assessment of the mucosal surface or for evaluation of the ductal systems during endoscopic retrograde cholangiopancreatography.

\section{Examination of the gut wall}

The upper digestive tract from esophagus to proximal half of the duodenum, as well as the rectum, can be easily accessed and examined using a radial echoendoscope, which provides a better overview than a linear echoendoscope. To better improve the EUS view of the mucosa and reduce the amount of water that has to be instilled into the lumen, a balloon is usually attached

Correspondence to: Tiing Leong Ang

Department of Gastroenterology and Hepatology, Changi General Hospital, 2 Simei Street 3, Singapore 529889

Tel: +65-6850-3558, Fax: +65-6781-6202, E-mail: tiing_leong_ang@cgh.com.sg

Received on August 1, 2017. Revised on September 3, 2017. Accepted on October 10, 2017. Published online January 3, 2018

pISSN 1976-2283 eISSN 2005-1212 https://doi.org/10.5009/gnl17348

@ This is an Open Access article distributed under the terms of the Creative Commons Attribution Non-Commercial License (http://creativecommons.org/licenses/by-nc/4.0) which permits unrestricted non-commercial use, distribution, and reproduction in any medium, provided the original work is properly cited. 


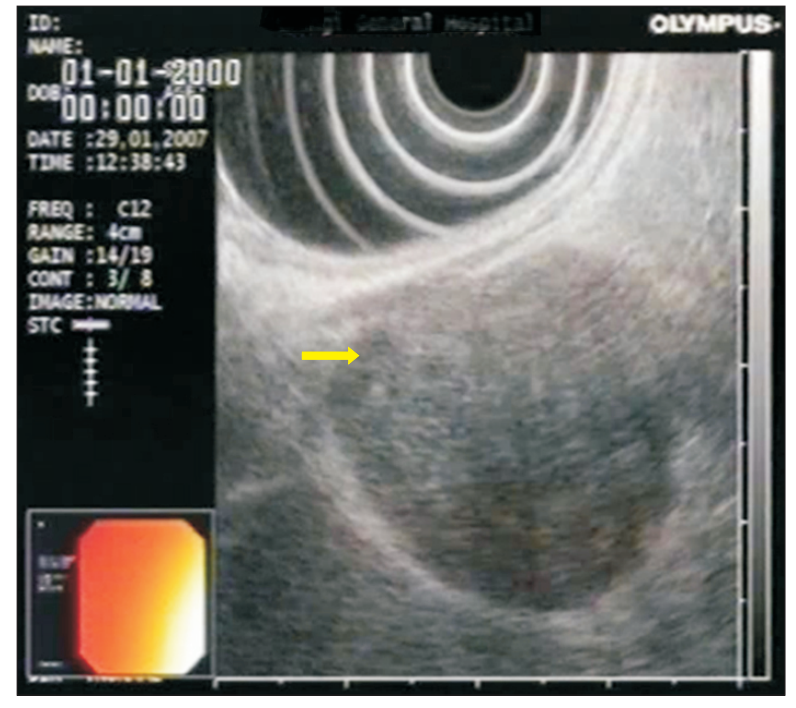

Fig. 1. Gastric gastrointestinal stromal tumor: hypoechoic mass arising from the muscularis propria (arrow).

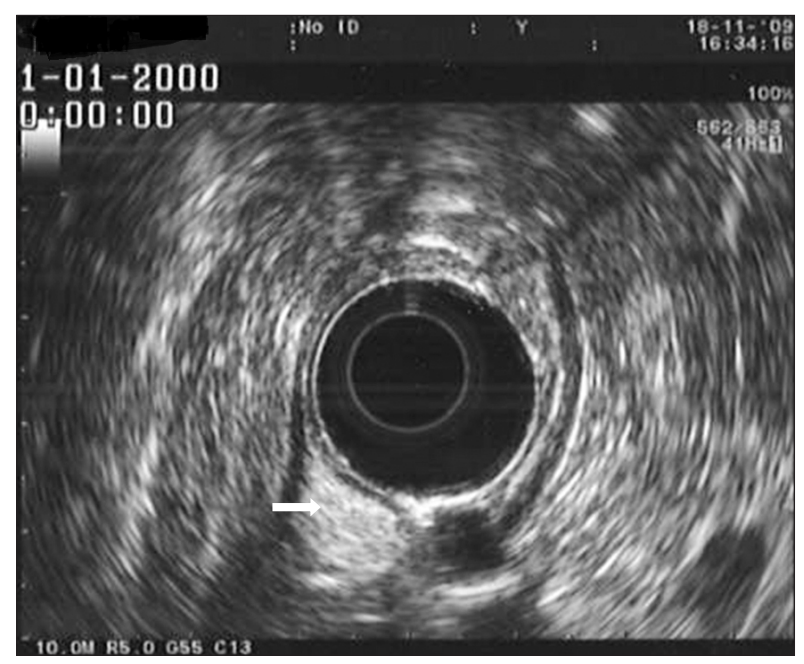

Fig. 2. Gastric lipoma: hyperechoic mass within the submucosa (arrow).

to the tip of the echoendoscope and distended using water. It is important to recognize the normal five layers of the gut wall, in order to diagnose subepithelial lesions and to accurately perform T-staging. Subepithelial lesions can be diagnosed based on their location within the gut wall layer and specific echogenicity. ${ }^{5}$ Examples include cyst which is an anechoic lesion within the submucosa; a muscle tumor be it a leiomyoma or gastrointestinal stromal tumor which is a hypoechoic lesion arising from the muscularis mucosae or propria (Fig. 1); a lipoma which manifests as a echogenic lesion arising from the submucosa (Fig. 2). T-staging will be determined by breach of the specific wall layer which the mucosa lesion invades (Fig. 3).

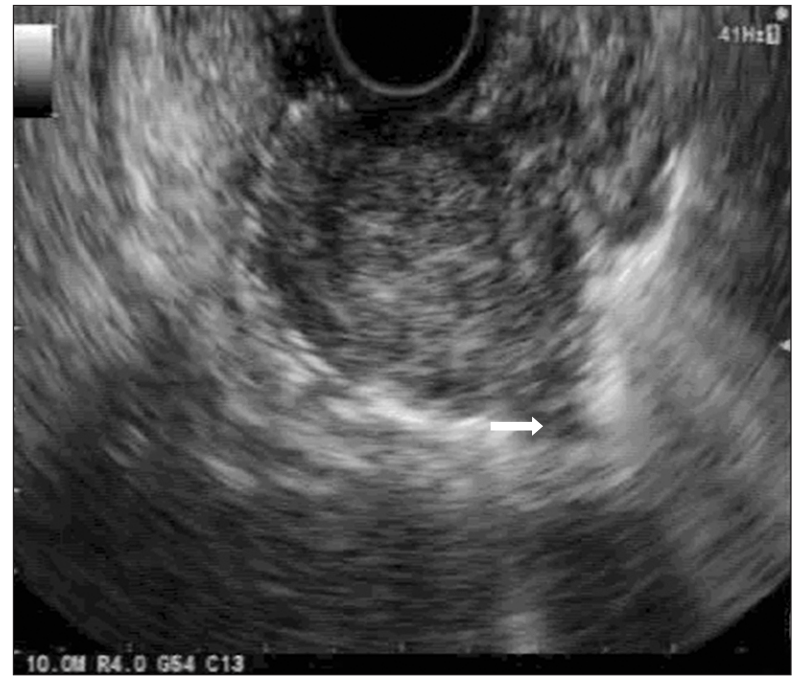

Fig. 3. Gastric adenocarcinoma: serosa involvement (arrow).

\section{Examination of the pancreaticobiliary system}

For the beginners, it is preferred that they subdivide pancreaticobiliary EUS examination into three stations where there are well-established landmarks for purpose of orientation to facilitate the learning process. ${ }^{6,7}$ The stations are the stomach (where the neck, body and tail of pancreas, the abdominal aorta with the celiac axis, portal confluence and splenic vein and artery, left kidney, spleen and left lobe of liver can be visualized) (Figs 4 and 5), the duodenal bulb (where the portal vein, bile duct and head of pancreas can be visualized) (Fig. 6) and D2/D3 (where the uncinate process and ampulla, including convergence of the bile duct and pancreatic duct can be visualized). Once expertise is acquired, it is possible to focus on the region of interest directly, or to insert the echoendoscope to D3 and slowly withdraw into the stomach, such that the pancreas can be traced sequentially in its entirety from the uncinate process to the tail. Vessels and landmarks can be easily recognized and used for orientation.

\section{EUS-guided fine needle aspiration and biopsy}

Currently dedicated needles for both EUS-guided fine needle aspiration (EUSFNA) and EUS-guided fine needle biopsy (EUSFNB) are available. In the initial phase of development, only EUSFNA needles were available, and the needle size ranged from 19, 22 to 25 gauge. Subsequently a 20-gauge Trucut biopsy (EUSTCB) needle (QuickCore ${ }^{\circledR}$ needle; Cook Medical Inc., Winston-Salem, NC, USA) was developed, but due to its springloaded firing mechanism it was cumbersome to use and is no longer in production. This has since been replaced by other biopsy needles where special cutting mechanisms at the needle tip allows acquisition of a core tissue and these newer biopsy needles are as easy to use as the EUSFNA needles. Examples include the Procore ${ }^{\circledR}$ needle which is characterized by a cut- 

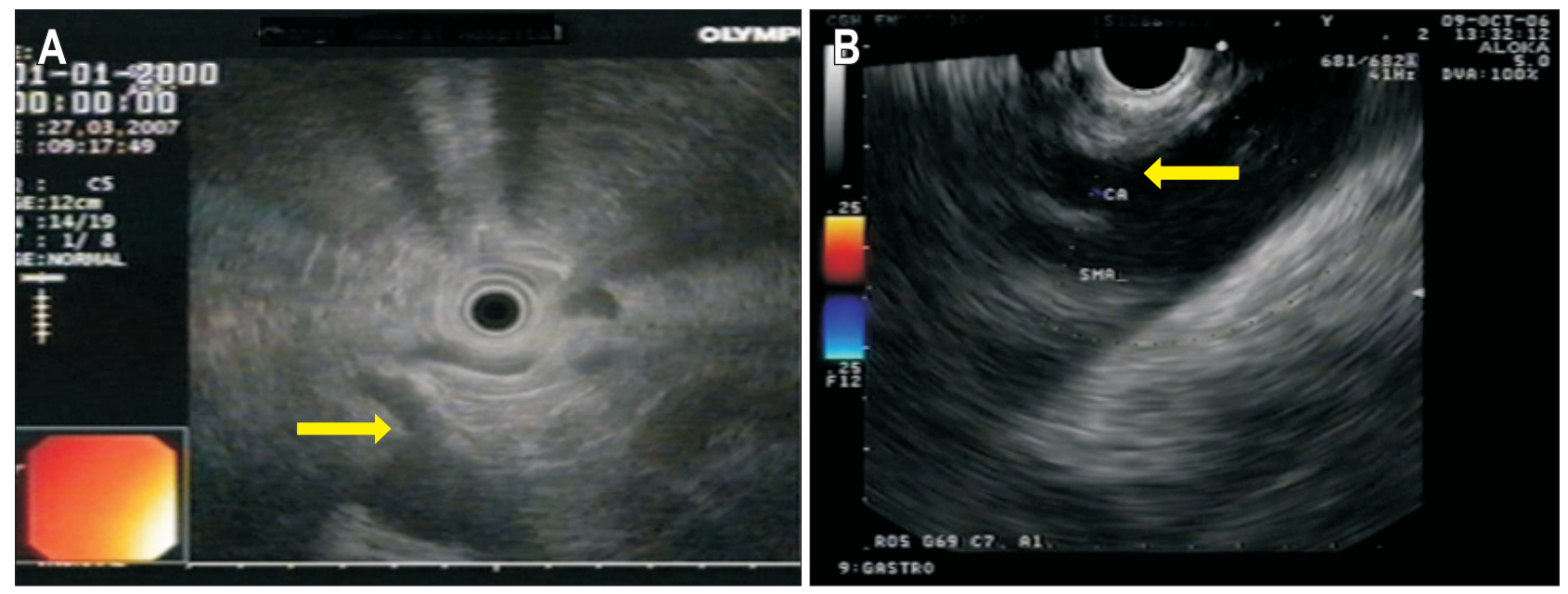

Fig. 4. (A) Radial and (B) linear endoscopic ultrasound (EUS) view from the stomach: celiac axis (arrow).
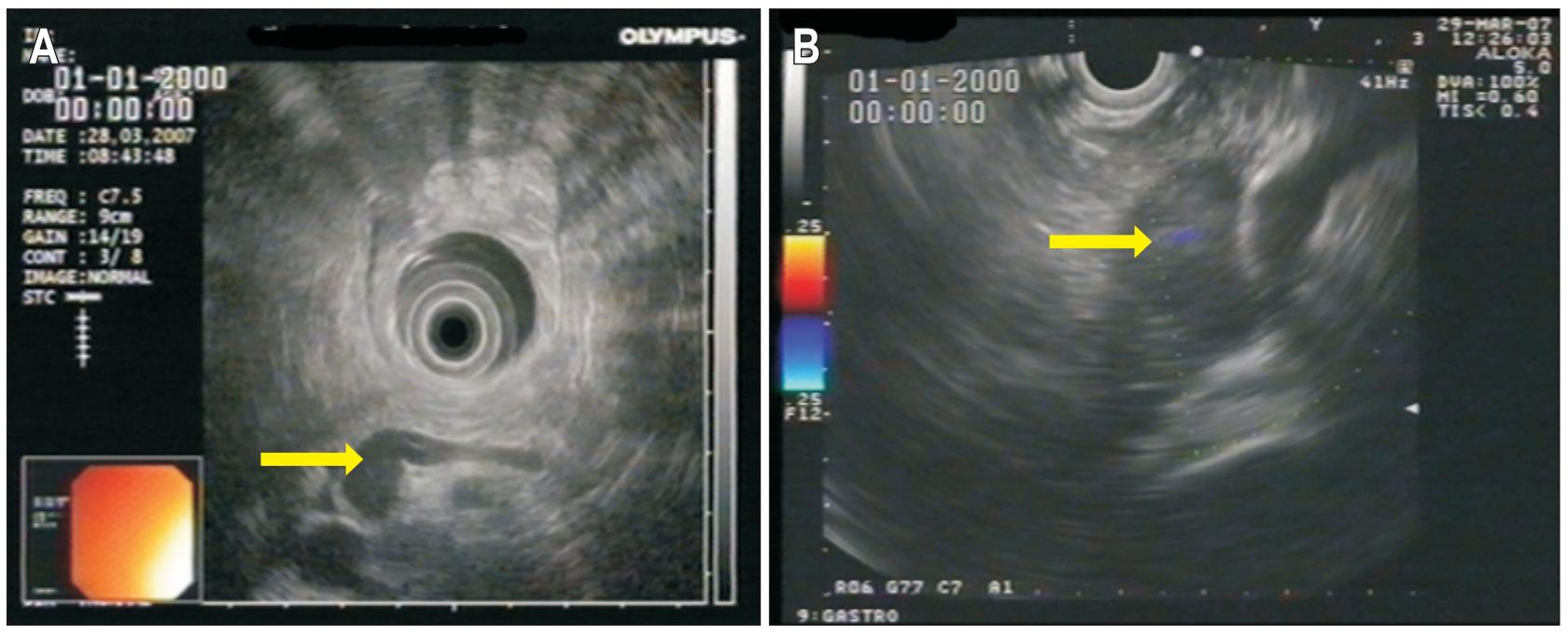

Fig. 5. (A) Radial and (B) linear endoscopic ultrasound (EUS) view from the stomach: portal confluence (arrow).
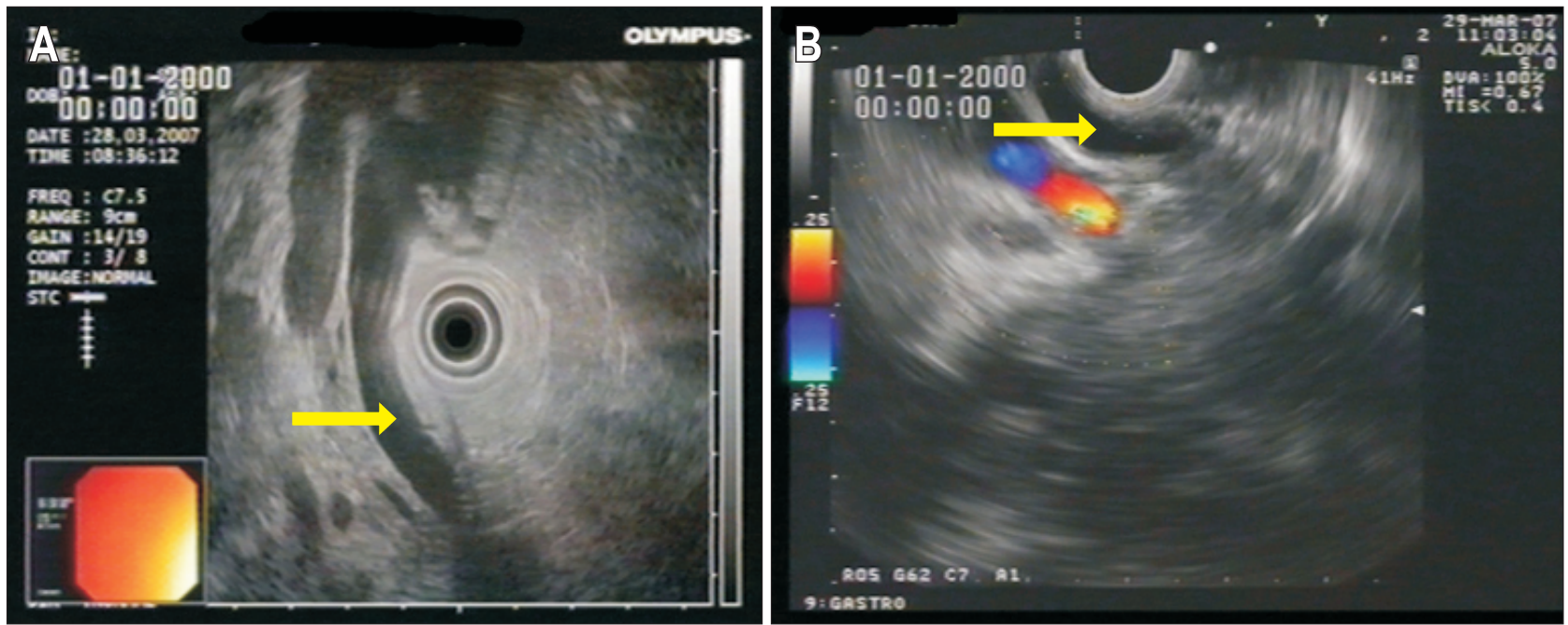

Fig. 6. (A) Radial and (B) linear endoscopic ultrasound (EUS) view from duodenal bulb: portal vein and bile duct (arrow). 
ting bevel (reverse for 19, 22 and 25-gauge and forward for 20-gauge needles) at the needle tip (Cook Medical Inc.), the Acquire $^{\mathrm{TM}}$ needle which is characterized by a 3 point needle tip (size, 22 and 25 gauge; Boston Scientific Corp., Marlborough, MA, USA) and the SharkCore ${ }^{\mathrm{TM}}$ needle which characterized by six distal cutting edges at the needle tip (size, 22 and 25 gauge; Medtronic, Minneapolis, MN, USA).

To perform the actual EUSFNA or EUSFNB procedure, the target lesion is visualized using a linear echoendoscope, interposed vessels excluded by use of color Doppler, and the puncture needle is inserted into the accessory channel of the echoendoscope, and under real time ultrasound guidance, the lesion is punctured (Fig. 7) and sampled with or without vacuum suction by a series of in and out needle passes directed in multiple directions within the target lesion, the so-called fanning technique. The aspirate acquired is then expressed out onto glass slides for cytology smears or onto strips of filter paper to be immersed in formalin in the case of tissue biopsy. Having the presence of rapid on-site cytological examination (ROSE) by a cytotechnician or cytopathologist may help in real time assessment of cytological smear adequacy, but this adds to procedural costs, and when this is not available, performing a minimum set of punctures or sending for histology when there is core tissue should provide equivalent sample yield. ${ }^{8,9}$

\section{OUTCOME DATA FOR DIAGNOSTIC EUS}

\section{EUS outcome data for luminal cancer T-staging}

The EUS transducer can clearly visualize the different layers of the gut wall, and thus provides highly accurate assessment during T-staging of luminal malignancies. The main limitation is when the lesion cannot be accessed and properly examined, either due to stenosis or altered postsurgery anatomy. It must be

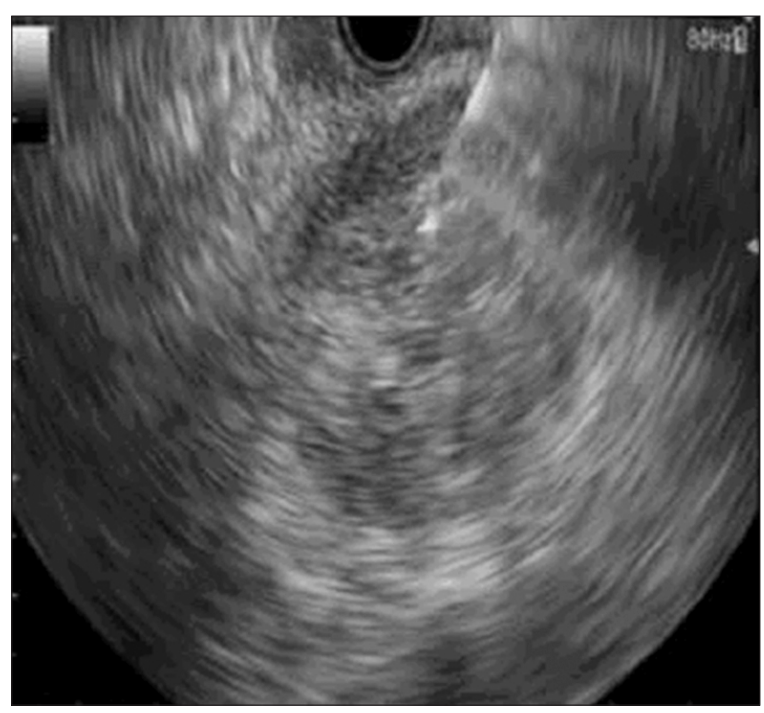

Fig. 7. Endoscopic ultrasound-guided fine needle aspiration of pancreatic adenocarcinoma. acknowledged that EUS has been compared with high resolution and magnifying endoscopy for predicting invasion depth in early esophageal ${ }^{10-12}$ and gastric cancer ${ }^{13-15}$ and the results were comparable. This suggests that routine EUS evaluation prior to endoscopic resection may not be always necessary. However, EUS will still provide useful additional information if there is uncertainty about the depth of involvement from magnifying endoscopy when endoscopic resection is being considered. ${ }^{16}$ For esophageal cancer, curative endoscopic resection is only possible for $\mathrm{m} 1$ (carcinoma in situ) and $\mathrm{m} 2$ (invasion of lamina propria) lesions, but not for $\mathrm{m} 3$ (invasion of muscularis mucosa) cancer as there is a risk of nodal metastasis. ${ }^{17}$ In the case of gastric cancer, endoscopic resection is only curative for lesions that invade less than $500 \mu \mathrm{m}$ into the submucosa. ${ }^{18}$ EUS can readily differentiate lesions confined to the mucosa from those that have invaded deeply into the submucosa. However, overestimation of the depth may arise due to underlying inflammation, and in such borderline situations, if the lesion can be elevated by submucosal injection, endoscopic resection may still be attempted with certainty of cure only after histopathological assessment. EUS complements other cross sectional imaging modalities such as CT and magnetic resonance imaging (MRI).

In the case of esophageal cancer, results of pooled sensitivity/specificity data from meta-analysis for T-staging were T1: 81.6\% (95\% confidence interval [CI], 77.8 to 84.9)/99.4\% (95\% CI, 99.0 to 99.7); T2: $81.4 \%$ (95\% CI, 77.5 to 84.8$) / 96.3 \%$ (95\% CI, 95.4 to 97.1 ); T3: $91.4 \%$ (95\% CI, 89.5 to 93.0$) / 94.4 \%$ (95\% CI, 93.1 to 95.5 ); T4: $92.4 \%$ (95\% CI, 89.2 to 95.0$) / 97.4 \%$ (95\% CI, 96.6 to 98.0$).{ }^{19}$ EUS was useful to differentiate mucosal from submucosal tumors, with sensitivity/specificity for T1a and T1b being 85\% (95\% CI, 82 to 88)/87\% (95\% CI, 84 to 90) and $86 \%$ (95\% CI, 82 to 89 )/86\% (95\% CI, 83 to 89 ) respectively. ${ }^{20}$ This can help identify patients who will not benefit from mini-

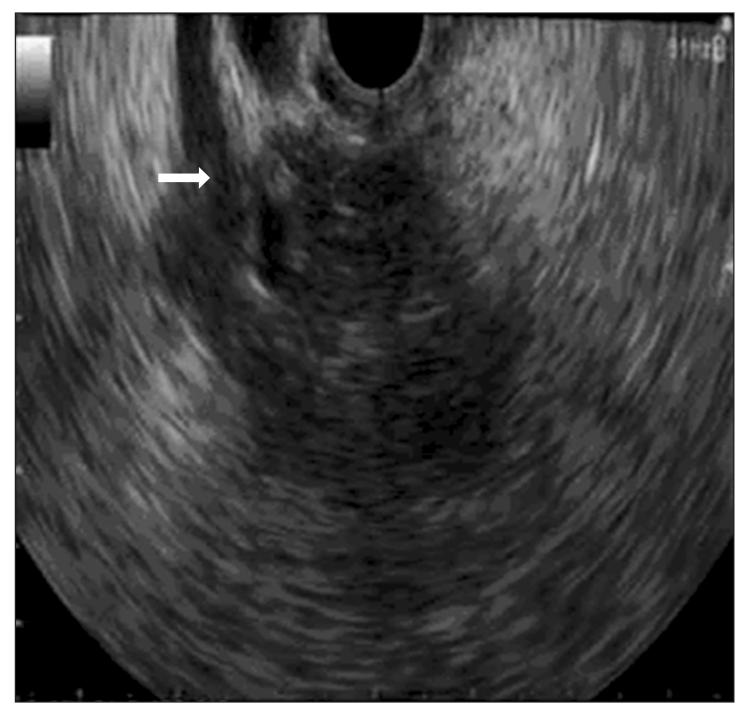

Fig. 8. Endoscopic ultrasound view of portal vein invasion by pancreatic adenocarcinoma (arrow). 
mally invasive endoscopic treatment. A meta-analysis reported that among patients with Barrett's esophagus and high-grade dysplasia/early adenocarcinoma, 14\% (95\% CI, 8 to 22) had advanced disease detected on EUS. ${ }^{21}$ After neoadjuvant therapy the results of EUS reassessment are more modest, with sensitivity/specificity being T1: 23\% (95\% CI, 16 to 32)/95\% (95\% CI, 93 to 97 ); T2: 29\% (95\% CI, 19 to 41$) / 84 \%$ (95\% CI, 77 to 88); T3: 81\% (95\% CI, 72 to 88)/42\% (95\% CI, 33 to 52); T4: 43\% (95\% CI, 31 to 56)/96\% (95\% CI, 94 to 97). ${ }^{22}$

In the case of gastric cancer, meta-analysis reported the sensitivity and specificity of EUS in discriminating T1 to T2 versus T3 to T4 gastric cancer to be $86 \%$ (95\% CI, 81 to 90) and 90\% (95\% CI, 87 to 93) respectively. For the diagnostic capacity of EUS to distinguish T1 versus T2 tumors, the sensitivity and specificity were 85\% (95\% CI, 78 to 91) and 90\% (95\% CI, 85 to 93) respectively. In terms of differentiation of the capacity of EUS to distinguish between T1a (mucosal) versus T1b (submucosal) cancers the sensitivity and specificity were 87\% (95\% CI, 81 to 92 ) and 75\% (95\% CI, 62 to 84 ) respectively. ${ }^{23}$

In T-staging for rectal cancer, the pooled sensitivity/specificity of EUS were T1 87.8\% (95\% CI, 85.3 to 90.0)/ 98.3\% (95\% CI, 97.8 to 98.7); T2: 80.5\% (95\% CI, 77.9 to 82.9)/95.6\% (95\% CI, 94.9 to 96.3 ); T3: $96.4 \%$ (95\% CI, 95.4 to 97.2$) / 90.6 \%$ (95\% CI, 89.5 to 91.7 ); T4: $95.4 \%$ (95\% CI, 92.4 to 97.5$) / 98.3 \%$ (95\% CI, 97.8 to 98.7$){ }^{24}$

\section{EUS outcome data for pancreatic cancer}

EUS is clearly superior to cross sectional imaging such as CT and MRI for detection of solid pancreatic lesions smaller than 20 to $30 \mathrm{~mm} .{ }^{25}$ One study reported that for pancreatic tumors smaller than $15 \mathrm{~mm}$, EUS detected 100\% of cases (95\% CI, 54 to 100) compared to $67 \%$ (95\% CI, 22 to 96) for dual phase helical $\mathrm{CT}^{26}$ A recent multicenter prospective study compared

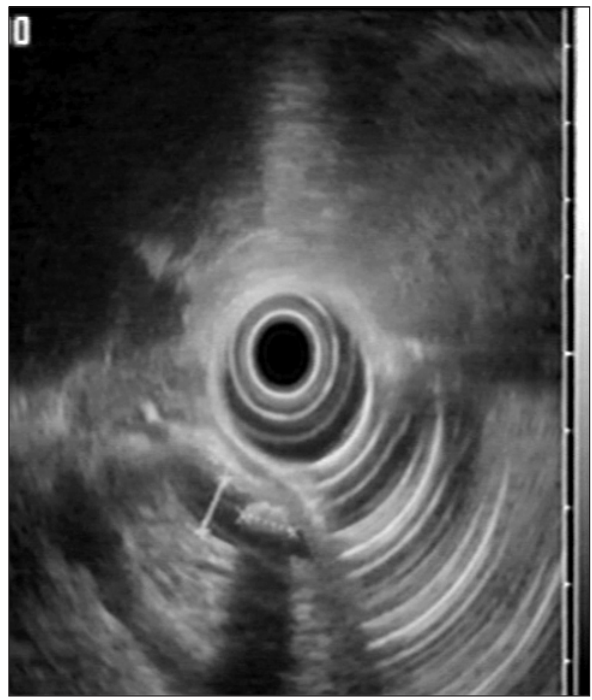

Fig. 9. Endoscopic ultrasound view of common bile duct stone. the use of EUS and MRI for pancreatic cancer screening in 139 individuals at high risk ( $>10$-fold increased risk) for pancreatic cancer. Two solid lesions (mean size, $9 \mathrm{~mm}$ ) were detected only by EUS (a stage I pancreatic cancer and a multifocal pancreatic intraepithelial neoplasia). ${ }^{27}$

The preoperative evaluation of pancreatic cancer serves to guide further management based on the resectability status which is based on assessment of vascular (arterial/venous) involvement and distant metastases including celiac axis node involvement. Pooled analysis reported 73\% sensitivity and 90\% specificity of EUS for vascular invasion (Fig. 8). ${ }^{28}$ The following features on EUS predict the presence of vascular invasion: (1) peripancreatic venous collaterals in an area of a mass that obliterates the normal anatomic location of a major vessel; (2) tumor within the vessel lumen; (3) abnormal vessel contour or irregular wall with loss of the vessel-parenchymal sonographic interface. ${ }^{29}$ When compared with CT, EUS had superior accuracy to CT for T staging (67\% vs $41 \%$ ) but similar accuracy to CT for $\mathrm{N}$ staging (44\% vs $47 \%$ ), detection of resectable tumors (88\% vs $92 \%$ ) and unresectable tumors (68\% vs $64 \%$ ). ${ }^{30}$ In assessing vascular invasion, EUS had sensitivity of $61 \%$ and specificity of $90 \%$, while CT had sensitivity of 56\% and specificity of 93\%. EUS has been shown to assess venous invasion better than arterial invasion. ${ }^{32}$ MRI has lower sensitivity (15\% vs 36\%) but higher specificity (93\% vs $87 \%$ ) than EUS for N-staging. ${ }^{33}$ MRI has higher sensitivity (59\% vs $42 \%$ ) but lower specificity (84\% vs $97 \%$ ) than EUS for vascular invasion.

\section{EUS outcome data for benign pancreaticobiliary diseases}

EUS has $89 \%$ to $94 \%$ sensitivity and $94 \%$ to $95 \%$ specificity for detecting choledocholithiasis (Fig. 9), ${ }^{34,35}$ which is superior to that of transabdominal ultrasonography (sensitivity, 63\%; speci-

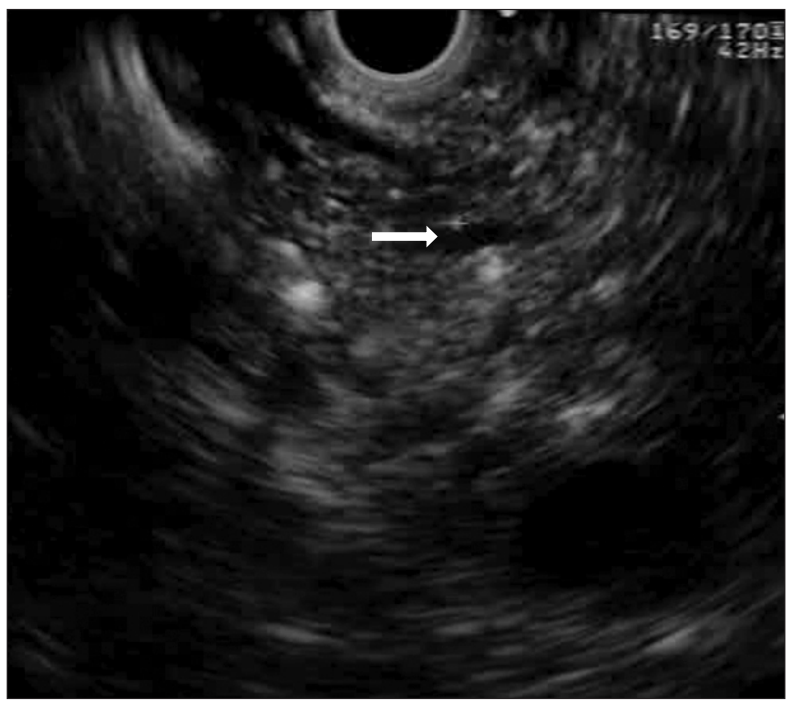

Fig. 10. Endoscopic ultrasound appearance of chronic pancreatitis with hyperechoic strands, parenchymal lobularity and calcifications and dilated pancreatic duct (arrow). 
ficity, 95\%) and CT (sensitivity, 71\%; specificity, 97\%). ${ }^{36}$ Overall the performance of EUS and magnetic resonance cholangiopancreatography (MRCP) are similar. ${ }^{37}$ MRCP has 85\% to 92\% sensitivity and $93 \%$ to $97 \%$ specificity for choledocholithiasis. ${ }^{38,39}$ However, in the setting of small $(<6 \mathrm{~mm})$ stones, MRCP has a lower sensitivity that range from $33 \%$ to $71 \% .{ }^{40-42}$ However, smaller stone size does not affect the accuracy of EUS. ${ }^{43} \mathrm{Al}-$ though radial EUS provides a better over of the entire bile duct, linear EUS has equivalent accuracy in detecting choledocholithiasis. ${ }^{44}$ It is important that the bile duct be evaluated carefully and traced down till the major papilla, where an impacted stone may be detected on occasion.

Chronic pancreatitis can be easily diagnosed when there are clinical features of maldigestion with overt radiological features of pancreatic atrophy and calcification. Making a diagnosis may be more challenging in absence of such advanced features. EUS is a very sensitive tool and utilizes pancreatic duct and parenchyma changes for diagnosis (Fig. 10). EUS parenchymal features in chronic pancreatitis include hyperechoic foci, hyperechoic strands, lobularity, and cysts while ductal features include main duct dilation, duct irregularity, hyperechoic duct margins, visible side branches, and stones. ${ }^{45}$ A consensus-based criteria for EUS features of chronic pancreatitis (Rosemont classification) has been developed where different weights are assigned to conventional parenchymal and ductal features of chronic pancreatitis to optimize diagnostic accuracy. ${ }^{46}$ Moderate to substantial inter-observer agreement can be achieved with these criteria. ${ }^{47,48}$ The Rosemont criteria have been compared to conventional EUS criteria and found to be more stringent, and thus may reduce the false positive diagnostic rates in context of early chronic pancreatitis. ${ }^{49,50}$ Defining the sensitivity of EUS criteria is challenging as a true gold standard comparator has been difficult to identify because pancreatic function tests, pancreatography, and histology may not recognize mild or moderate chronic pancreatitis. It is important to look at the clinical context to avoid over-diagnosis of chronic pancreatitis as mild parenchymal changes may actually be due to other etiologies such as recent or active acute pancreatitis, normal aging, to-

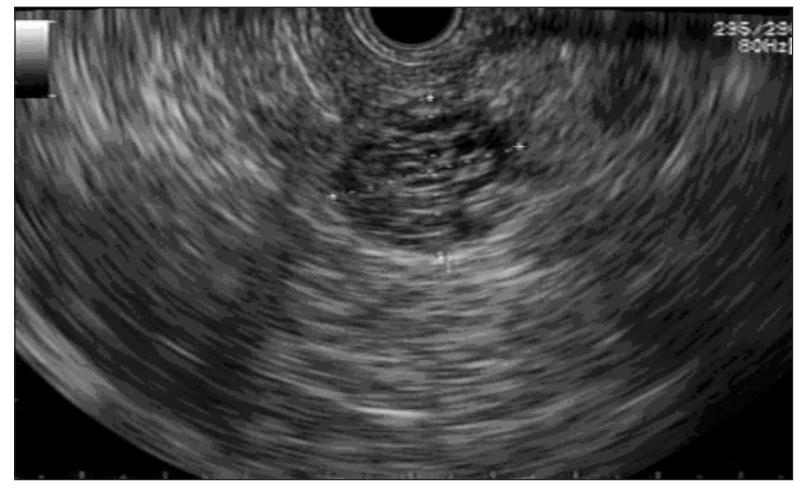

Fig. 11. Serous cystadenoma. bacco use, obesity, or alcohol use.

\section{EUS outcome data for pancreatic cystic neoplasm}

EUS is of relevance in the evaluation of suspected pancreatic cystic neoplasms in terms of differentiation from nonneoplastic types of pancreatic cysts and to characterize the type of cystic neoplasm. It has been reported that a cystic lesion without septa or solid components within a pancreas having parenchymal features suggestive of pancreatitis (calcifications, atrophy, or a change in echo texture) indicates a pseudocyst with a sensitivity of $94 \%$ and a specificity of $85 \% .^{51}$ Mucinous cystic neoplasms have malignant potential, in contrast to non-mucinous lesions and hence need to be properly characterized for subsequent management, be it surveillance or surgical resection. Pancreatic cystic neoplasms may have characteristic EUS features. Microcystic morphology suggests a serous cystic neoplasm with an accuracy of $92 \%$ to $96 \%$ (Fig. 11). ${ }^{52}$ This is not seen in a mucinous cystic neoplasm which is typically macrocystic without internal septa (Fig. 12). ${ }^{53}$ Intraductal papillary mucinous neoplasia (IPMN) may be characterized by cystic lesions arising from a non-dilated or dilated main pancreatic duct. However EUS features may not always be classical and when surgical histology was used as a reference standard, the overall diagnostic accuracy of EUS imaging ranged from $40 \%$ to $96 \%$. $^{54}$ Morphological features such as presence of intramural nodules and adjacent solid lesions are features suggestive of malignant transformation in mucinous cystic neoplasms. A meta-analysis found that mural nodule, main pancreatic duct dilation, thickened septal walls, and cyst size $>3 \mathrm{~cm}$ on radiologic or EUS imaging were independent predictors of malignant branch-duct IPMN. ${ }^{55}$ The Fukuoka international consensus guidelines have identified a main pancreatic duct size $>10 \mathrm{~mm}$ or the presence of an enhancing solid component on radiologic imaging as high-risk stigmata. Lower risk worrisome features included a cyst size of $>3 \mathrm{~cm}$, thickened enhancing cyst walls, nonenhancing mural nodules, main pancreatic duct size of 5 to 9 $\mathrm{mm}$, an abrupt change in the main pancreatic duct caliber with upstream pancreatic atrophy, or the presence of peripancreatic

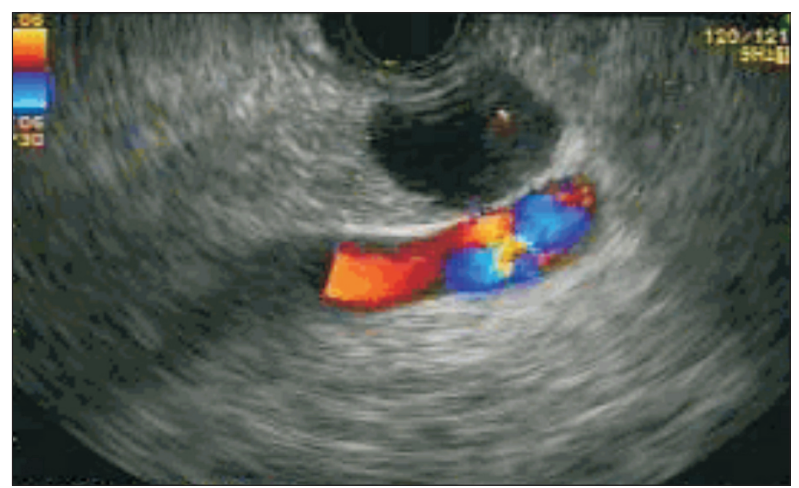

Fig. 12. Mucinous cystic neoplasm. 
lymphadenopathy. ${ }^{56}$ It must be remembered that small cyst size alone does not exclude malignancy and the presence or absence of symptoms must be considered. It has been reported that 20\% of lesions $2 \mathrm{~cm}$ or smaller were malignant, and an additional $45 \%$ of lesions had malignant potential. However, only 3.5\% of asymptomatic lesions $<2 \mathrm{~cm}$ was malignant. ${ }^{57}$

The yield of cytology from EUSFNA of pancreatic cystic neoplasms is generally poor unless the cyst wall, septa or solid lesions can be specially targeted. It is specific but not sensitive. Hence, EUSFNA of cystic neoplasms for biochemical testing of aspirated fluid is important. ${ }^{58}$ In general, to have an adequate volume of fluid for analysis, the cyst size should be greater than $1 \mathrm{~cm}$. In practice, only larger cysts greater than 2 to $3 \mathrm{~cm}$ actually need EUSFNA for further analysis. The most crucial test is the fluid carcinoembryonic antigen (CEA); other tumor markers studied have included CA 19-9, CA 125, CA 72-4, and CA 15-3 but these are not considered to be sufficiently accurate. ${ }^{58}$ The optimal CEA cutoff for differentiating mucinous from nonmucinous cysts has been suggested to be $192 \mathrm{ng} / \mathrm{mL}$, providing a sensitivity of 75\% and a specificity of $84 \% .{ }^{54}$ Elevated fluid amylase levels will provide an indication of communication with the main pancreatic duct such as in the case of IPMN and will be elevated in pseudocysts. A recent meta-analysis of aspirates from EUSFNA found CEA to have a sensitivity of 63\% (95\% CI, 59\% to 67\%) and specificity of $88 \%$ (95\% CI, 83\% to 91\%) for the identification of mucinous cystic tumors. ${ }^{59}$ It has been suggested that when available molecular testing of the cyst fluid be considered when initial ancillary testing of cytology and CEA is inconclusive and when test results may alter management. Molecular testing however is mainly a research tool currently. ${ }^{58}$

\section{OUTCOME DATA FOR EUS-GUIDED DIAGNOSTIC TISSUE ACQUISITION}

\section{Overall diagnostic yield of EUSFNA}

In prospective trials, EUSFNA has been clearly established to be an important diagnostic tool, with excellent diagnostic yield and safety profile. ${ }^{8,60}$ In a meta-analysis that examined the diagnostic accuracy of EUSFNA for staging mediastinal lymph nodes in patients with lung cancer, the sensitivity was 83\% (95\% CI, 78 to 87) and specificity was $97 \%$ (95\% CI, 96 to 98). ${ }^{61}$ In another meta-analysis that focused on EUSFNA of pancreatic masses, the sensitivity for diagnosing the correct etiology was $86.8 \%$ (95\% CI, 85.5 to 87.9 ) and the specificity was 95.8\% (95\% CI, 94.6 to 96.7$).{ }^{62}$

\section{Techniques to improve diagnostic yield}

The following techniques have been used for increasing the accuracy of EUSFNA/EUSFNB: (1) fanning technique; (2) individualizing use of suction; (3) wet suction technique; (4) slow pull technique; (5) ROSE; and (6) minimum number of needle passes in absence of ROSE. The outcome data for these indi- vidual techniques will be reviewed.

The fanning technique involves positioning the needle at different areas within a mass and then moving the needle back and forth in each area to obtain tissue. Aspiration is initiated at a margin of the lesion and then "fanned" until the opposite margin is sampled. In a randomized controlled trial of 54 patients with solid pancreatic masses, the fanning technique resulted in a significantly higher first pass diagnosis compared with the standard FNA technique (85.7\% vs 57.7\%, $\mathrm{p}=0.02$ ). ${ }^{63}$

Applying suction during EUSFNA increases the quantity of the sample at the expense of possible increased bloodiness. In the context of EUSFNA of lymph nodes, a randomized trial demonstrated that suction resulted in a bloodier specimen with no difference in diagnostic accuracy ${ }^{64}$ In a randomized trial of EUSFNA of pancreatic masses, there was no difference in degree of bloodiness with or without suction, although the sensitivity and the negative predictive values were higher when suction was applied (85.7\% vs $66.7 \%, \mathrm{p}=0.05) .{ }^{65}$ On the other hand, a randomized trial of 81 patients with pancreatic masses who underwent EUSFNA with and without suction demonstrated that suction resulted in higher diagnostic samples $(72.8 \%$ vs $58.6 \%$, $\mathrm{p}=0.001$ ) and cellularity (odds ratio [OR], 2.12; 95\% CI, 1.37 to 3.30; $\mathrm{p}<0.001$ ) although specimen bloodiness was increased. ${ }^{66}$ The use of suction should probably be individualized and utilized in lesions such hard fibrotic masses, suspected pancreatic cancer and mural mesenchymal tumors, while the initial pass into lymph nodes and suspected neuroendocrine tumors may be made without suction. ${ }^{8}$ Two modified FNA techniques were recently reported. The "slow pull" technique is performed by gradual withdrawal of the stylet as the needle is repeatedly passed through the target lesion in order to produce a low level of negative pressure within the needle which increases tissue acquisition and limits specimen bloodiness. In a retrospective study of 97 EUSFNA performed with either the slow pull technique or suction, when using a 25-gauge FNA needle the slow pull technique resulted in lower cellularity and bloodiness but higher diagnostic sensitivity; there was no difference with a 22-gauge needle. ${ }^{67}$ In the "wet suction" technique, the FNA needle is flushed with sterile saline prior to puncturing the target lesion, and suction is then applied. A randomized trial of EUSFNA of solid masses using either wet suction or conventional EUSFNA technique reported that wet suction resulted in a significantly better specimen adequacy (85.5\% vs 75.2\%, p<0.035), with no difference in the amount of blood contamination. ${ }^{68}$

ROSE has been advocated as a strategy to improve diagnostic yield. ROSE may improve procedural efficiency and reduce patient risk by limiting the number of needle passes. It has been reported that the presence of on-site cytopathologist leads to a $10 \%$ to $15 \%$ increase in diagnostic yield. ${ }^{69,70}$ An approximate $20 \%$ rate of nondiagnostic aspirates in the absence of ROSE has been reported. ${ }^{71}$ On the other hand, ROSE may not be feasible logistically and will increase procedural costs. Data have shown 
that when a minimum number of aspirations are performed, the diagnostic yield will be maximized. For solid pancreatic masses, Erickson et al. ${ }^{69}$ reported that well-differentiated pancreatic adenocarcinomas required a higher number of passes $(5.5 \pm 2.7)$ as compared to moderately $(2.7 \pm 1.2)$ and poorly $(2.3 \pm 1.1)$ differentiated tumors. Pellisé Urquiza et $a .^{72}$ reported that the accuracy of EUS-FNA for pancreatic masses reached a plateau at the fourth needle pass. Turner reported in a large cohort of 559 patients with a pancreatic mass that a diagnostic accuracy of about $80 \%$ could be obtained with only 2 to 3 needle passes. ${ }^{73}$ Lymph nodes generally require only 2 to 3 passes. ${ }^{64,69,74}$ Hence, it is recommended that in absence of ROSE, 4 to 5 passes in solid pancreatic lesions, and 2 to 3 passes in lymph nodes, liver, and adrenal lesions should be performed. ${ }^{8}$

\section{Impact of needle sizes}

Several studies have addressed the impact of needle size on diagnostic yield. A larger needle (19 gauge) will certainly obtain a higher amount of cellular material than thinner needles (22 and 25 gauge). However a 19 gauge-needle is stiffer and thus has a higher rate of technical failure for transduodenal EUSFNA. Additionally if cytology alone without histology is adequate for making a diagnosis, then the smaller amount of material from use of smaller 22 and 25-gauge needles would be sufficient and thus there would not be differences in diagnostic yield. Indeed most comparative studies of needles actually focused predominantly on suspected pancreatic cancer, where cytology would probably suffice, and thus not unexpectedly no differences were demonstrated. Two meta-analyses demonstrated slight superiority of the 25-gauge over the 22-gauge aspiration needles for EUSFNA of solid pancreatic lesions. ${ }^{75,76}$ Passage of the thinner 25-gauge needle is easier when the scope is angulated during transduodenal puncture of pancreatic head lesions, and into very firm lesions such as pancreatic cancer. For non-pancreatic lesions and lymph nodes, the diagnostic yields of 22 and 25-gauge needles are similar. ${ }^{77,78}$ The limited comparative data for 19-gauge needle suggested no incremental diagnostic yield of cytology compared with either 22 or 25 -gauge needles. ${ }^{75}$ Two randomized controlled trials compared the cytological yield of 22-gauge needles with and without a side-port and both demonstrated no differences. ${ }^{79,80}$

\section{EUSFNA versus EUSFNB}

Although excellent diagnostic accuracy can be achieved by cytology in most instances, tissue histology may be the preferred option in specific circumstances that require tissue architecture as part of the assessment and additional immunohistochemical studies such as in the case of gastrointestinal stromal tumor, lymphoma or autoimmune pancreatitis. Tissue biopsy may also be necessary as a salvage diagnostic tool after failed FNA or nondiagnostic cytology.

Dedicated EUS biopsy needles that are as easy to use as standard FNA needles are now available. Most of the currently published literature utilized the Procore ${ }^{\circledR}$ needles which were the first introduced. Limited data have emerged for the Acquire $^{\mathrm{TM}}$ and SharkCore ${ }^{\mathrm{TM}}$ biopsy needles. A multicenter cohort study reported that when the 19-gauge Procore ${ }^{\circledR}$ was used, adequate specimen for histology was obtained in $89.47 \%$ of cases (102/114), and that for the diagnosis of malignancy, the sensitivity was $90.2 \%$, specificity $100 \%$ and accuracy $92.9 \%{ }^{81}$ The Procore ${ }^{\circledR}$ needle has replaced the 19 -gauge EUSTCB needle which was the first commercially available EUS biopsy needle, because of its greater ease of use and clear superiority in terms of performance characteristics. A randomized controlled study that compared 19-gauge Procore ${ }^{\circledR}$ needle with 19-gauge EUSTCB demonstrated higher first pass technical success (95\% vs $78 \%, p=0.04$ ), higher rate of diagnostic histology (85\% vs $57 \%, \mathrm{p}=0.006$ ) and higher diagnostic accuracy (88\% vs $62 \%$, $\mathrm{p}=0.02){ }^{82}$ The 22-gauge Acquire ${ }^{\mathrm{TM}}$ biopsy needle was evaluated retrospectively in 59 consecutive patients with pancreatic solid lesions. A tissue core biopsy sample for histological evaluation was obtained in 55 cases (93.2\%). ${ }^{83}$ A retrospective study compared the performance of the SharkCore ${ }^{\mathrm{TM}}$ needles with EUSFNA needles for the diagnosis of solid upper gastrointestinal masses. More histological specimens were obtained with the SharkCore ${ }^{\mathrm{TM}}$ needles compared to EUSFNA needles (59\% vs 5\%, p<0.001), although diagnostic test characteristics were not significantly different (sensitivity, 91.5\% vs 85.7\%; specificity, 100\% vs 100\%; accuracy, 92.2 vs $85.4 \%$; p>0.05) in all cases. ${ }^{84}$ An animal experimental study to assess the core tissue acquisition ability of 20-gauge Procore ${ }^{\circledR}$ and 22-gauge Acquire ${ }^{\mathrm{TM}}$ needles reported that while the mean amount of core tissue score of the Acquire ${ }^{\mathrm{TM}}$ 22-gauge needle and Procore ${ }^{\circledR} 20$-gauge needle were significantly higher than that of the conventional 22-gauge needles, there was no significant difference in the mean amount of core tissue score between these two biopsy needles. ${ }^{85}$

Two recent meta-analyses compared EUSFNA with EUSFNB using the Procore ${ }^{\circledR}$ needles. ${ }^{86,87}$ The conclusion was that there was no significant difference in the diagnostic yield between EUSFNA and EUSFNB. However, it must be noted that the analyses focused mainly on pancreatic masses using the smaller 22 to 25-gauge needles, which are expected to result in a lower histological yield than the larger 20 to 19-gauge needles, where such randomized comparative data are lacking. In addition, having proper histological specimens is not crucial for diagnosis of pancreatic adenocarcinoma, unlike situations such as lymphoma and gastrointestinal stromal tumor, where the clear superiority of a biopsy needle has been demonstrated. ${ }^{88}$ The meta-analyses did reveal that fewer needle passes were required with EUSFNB, and although there was no significant difference in the diagnostic yield between EUSFNA and EUSFNB when EUSFNA was accompanied by ROSE, without ROSE EUSFNB was associated with a relatively better diagnostic adequacy in solid pancreatic lesions. ${ }^{86}$ This suggests that EUSFNB might be 
preferred if ROSE is not available.

In the context of subepithelial lesion evaluation, Kim et al. ${ }^{88}$ reported that the 22-gauge Procore ${ }^{\circledR}$ needle was shown to achieve a significantly higher yield of histological material and diagnostic yield compared to a 22-gauge FNA needle (75\% vs 20\%). Hedenström et al. ${ }^{89}$ also reported that EUSFNB using the 22 -gauge Procore ${ }^{\circledR}$ needle, when compared to the 22-gauge FNA needle, had superior sensitivity and accuracy (90\% vs 52\% and $83 \%$ vs $49 \%$, both $\mathrm{p}<0.001$ ) when evaluating subepithelial lesions. El Chafic et al. ${ }^{90}$ compared the SharkCore $^{\mathrm{TM}}$ biopsy needle with a standard EUSFNA needle in cases of suspected gastrointestinal stromal tumors adequate tissue was procured, allowing immunohistochemical staining in 59 patients (64.8\%) in the EUSFNA group and 15 patients (100\%) in the EUSFNB group ( $p=0.006$ ). A diagnosis was reached by immunohistochemical staining in 48 patients (52.7\%) in the EUSFNA group and 13 patients (86.7\%) in the EUSFNB group ( $p=0.01$ ). Adequate tissue was procured on the first pass of the EUSFNB needle in the majority of patients whereas a median of 3 passes was required with the EUSFNA needle. ${ }^{90}$

\section{Safety of EUSFNA/EUSFNB}

The safety profile of EUSFNA is excellent. ${ }^{91}$ Comparative studies of EUSFNA and EUSFNB did not show increased risk with EUSFNB. ${ }^{82,83,86-90}$ A systemic review (51 studies, 10,941 patients) reported that the overall rate of EUSFNA-specific morbidity was $0.98 \%$, with acute pancreatitis rate of $0.44 \%$ and postprocedure pain occurring in $0.34 \%$. The mortality rate attributable to EUS-FNA-specific morbidity was $0.02 \%{ }^{92}$ Another systemic review that focused on EUSFNA of pancreatic cystic lesions (40 studies, 5,124 patients) reported overall morbidity of $2.66 \%$ and mortality of $0.19 \%$. Common postprocedure adverse events included pancreatitis of $0.92 \%$, hemorrhage of $0.69 \%$, pain of $0.49 \%$, infection of $0.44 \%$, desaturation of $0.23 \%$ and perforation of $0.21 \% .^{93}$

\section{FUTURE DIRECTION}

\section{Contrast harmonic EUS and EUS elastography}

CHEUS and EUS elastography have been the subject of research and actual clinical application for several years but the use had been limited due to lack of standardization and availability in the standard EUS systems. However with greater availability of the required software in the Hitachi, Aloka and Olympus platforms, there is a potential for these image enhancement technologies to better complement diagnostic EUS imaging in routine clinical practice.

CHEUS works on the principle of enhanced echogenicity created by nonlinear oscillations when microbubbles that have been injected intravenously are exposed to ultrasonic waves within the microvessels of the target tissue. Background tissue signals are automatically subtracted, and only signals from the contrast agent are enhanced. This allows dynamic observation of microvessels with slow flows that are not revealed by Doppler color, which differentiates perfused and non-perfused tissue. This will unfortunately also reduce the image resolution. The contrast agents most commonly used are Sonovue (Bracco Imaging, Milan, Italy) which contains microbubbles of sulfur hexafluoride gas enclosed in a lipid shell, and Sonazoid (Daiichi-Sankyo, Tokyo, Japan), which contains perfluorobutane in a lipid shell. CHEUS is currently indicated for assessment of solid and cystic lesions of the pancreas, characterization of submucosal neoplasms, assessment of biliary neoplasms and assessment of lymph nodes. ${ }^{94}$ In the context of pancreatic masses, adenocarcinoma generally has inhomogeneous hypoenhancement, in contrast to hyperenhancement in context of inflammatory masses. ${ }^{95}$ A meta-analysis showed that hypoenhancement has a global sensitivity of $94 \%$ and a specificity of $89 \%$ for the diagnosis of pancreatic adenocarcinoma. ${ }^{96}$ In the case of pancreatic cystic neoplasms, CHEUS differentiates unenhanced mucus or debris from the mural nodules of malignant mucinous neoplasms or IPMN which are hyperenhanced. ${ }^{97}$ Abnormal microvessel enhancement highlighted by CHEUS has been used for the diagnosis of malignant gastrointestinal stromal tumors, malignant gallbladder wall thickening and malignant lymph nodes. ${ }^{98-100}$ Currently CHEUS is based on qualitative assessment. Attempts are being made to quantify the findings using dedicated software that can calculate time intensity curves but this remains investigational. ${ }^{95}$ Previously CHEUS was possible only with radial EUS. Now it is possible to perform CHEUS using linear EUS and this raises the potential for its use in complementing EUSFNA by highlighting lesions that may not be well seen in the regular EUS mode, such as small neuroendocrine tumors.

EUS elastography works by measuring the hardness or elasticity of tissue. The compression of a target tissue by an echoendoscopic probe produces a displacement of the tissue called "strain," which correlates with the hardness of the structure. In the earlier versions, evaluation was somewhat qualitative, by superimposing a colored image over the conventional grayscale EUS image in a region of interest. The strain level of hard tissue is colored in blue, and soft tissue is colored in green. It is possible now to perform some form of quantitative assessment by calculating the mean strain ratio within a selected area inside the region of interest as the difference in elasticity between the targeted lesion and the surrounding tissue. ${ }^{94}$ EUS elastography has been used for differentiation of benign and malignant pancreatic masses $^{101}$ and lymph nodes ${ }^{102}$ and for assessment of pancreatic fibrosis. ${ }^{103}$ A meta-analysis reported that the sensitivity and specificity for the diagnosis of malignant pancreatic masses were 98\% (95\% CI, 93 to 100) and 69\% (95\% CI, 52 to 82) for qualitative EUS elastography, and 96\% (95\% CI, 86 to 99) and $76 \%$ (95\% CI, 58 to 87 ) for quantitative EUS elastography, respectively. ${ }^{101}$ In another meta-analysis that evaluated EUS elastography for lymph node assessment, the pooled sensitiv- 


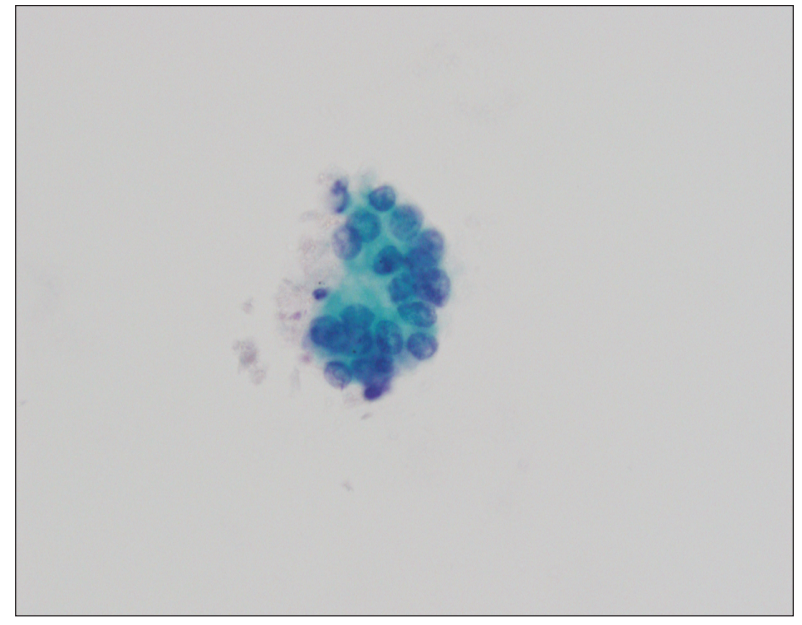

Fig. 13. Cytology of pancreatic adenocarcinoma acquired from endoscopic ultrasound-guided fine needle aspiration (PAP stain; $\times 600$ magnification).

ity of EUS elastography for the differential diagnosis of benign and malignant lymph nodes was 88\% (95\% CI, 83 to 92), and the specificity was $85 \%$ (95\% CI, 79 to 89$).{ }^{104}$ Similar to CHEUS, EUS elastography potentially can guide EUSFNA.

\section{EUSFNA or EUSFNB?}

In the past, only EUSFNA could be performed for tissue acquisition. The initial EUSFNB device was the EUSTCB needle and it was cumbersome and could not be used for all lesions. Currently there is a variety of EUSFNB needles available, with sizes ranging from 19 to 25 gauge. These needles are very easy to use, similar to EUSFNA needles. Studies have shown clearly that these needles can increase the rate of core tissue acquisition, and reduce the need for ROSE, without increasing patient risks. The only issue may be the slightly higher costs for each needle. An argument can be made that one should consider greater use of these biopsy needles. Tissue acquisition by EUSFNB when compared to cytology from EUSFNA is more reliable in providing an adequate sample for analysis. Microscopic evaluation of tissue histology is obviously superior to cytology with preserved architecture allowing more confident diagnoses, for example intraductal papillary mucinous neoplasm of the pancreas, and added tissue details such as desmoplastic or sclerotic stroma in pancreatic adenocarcinoma can be seen. Depending on the specimen sampled, EUSFNB tissue can occasionally provide unexpected non-favorable prognostic information such as the presence of vascular or perineural invasion in pancreatic carcinoma which is not possible with cytology (Figs 13 and 14). EUSFNB tissue core also has the added advantage of having sufficient yield and optimal tissue quality for ancillary tests such as immunohistochemical studies and molecular analysis. Performing immunohistochemical studies is an essential step in the work up of neuroendocrine and gastrointestinal stromal tumors, suggesting possible primary sites for metastatic lesions

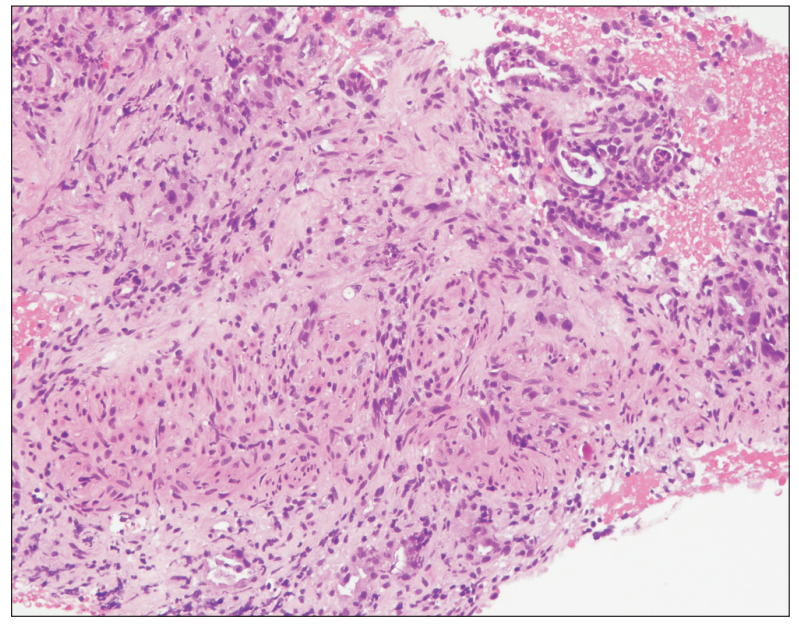

Fig. 14. Histology of pancreatic adenocarcinoma acquired from endoscopic ultrasound-guided fine needle biopsy illustrating desmoplastic stroma and vascular invasion (H \& E stain; ×100 magnification).

and distinguishing reactive lymph node versus low grade lymphoma. Molecular testing such as KIT and PGDFRA mutations in gastrointestinal stromal tumor can also be done on EUSFNB tissue. Finally a recognized constraint towards EUSFNA service is the availability of an experienced cytopathologist or equivalent to deliver high quality cytology reporting, whereas all qualified histopathologists are capable of tissue histology reporting to satisfactory standards.

\section{CONCLUSIONS}

Although there has been tremendous interest in therapeutic EUS in recent years, diagnostic EUS, including lesion sample acquisition, still constitute the majority of EUS procedures. It has excellent diagnostic performance characteristics, and ongoing technological progress has further improved image resolution, and now, allow additional image enhancement through CHEUS and EUS elastography. Tissue acquisition for diagnosis is an important component of diagnostic EUS and access to dedicated biopsy needles has further enhanced this ability.

\section{CONFLICTS OF INTEREST}

No potential conflict of interest relevant to this article was reported.

\section{REFERENCES}

1. Kohut M, Nowakowska-Duława E, Marek T, Kaczor R, Nowak A. Accuracy of linear endoscopic ultrasonography in the evaluation of patients with suspected common bile duct stones. Endoscopy 2002;34:299-303.

2. Stevens T, Zuccaro G Jr, Dumot JA, et al. Prospective comparison of radial and linear endoscopic ultrasound for diagnosis of 
chronic pancreatitis. Endoscopy 2009;41:836-841.

3. Kaneko M, Katanuma A, Maguchi H, et al. Prospective, randomized, comparative study of delineation capability of radial scanning and curved linear array endoscopic ultrasound for the pancreaticobiliary region. Endosc Int Open 2014;2:E160-E170.

4. Kanazawa K, Imazu H, Mori N, et al. A comparison of electronic radial and curvilinear endoscopic ultrasonography in the detection of pancreatic malignant tumor. Scand J Gastroenterol 2012;47:1313-1320.

5. Gong EJ, Kim DH. Endoscopic ultrasonography in the diagnosis of gastric subepithelial lesions. Clin Endosc 2016;49:425-433.

6. Inui K, Kida M, Fujita N, Maguchi H, Yasuda K, Yamao K. Standard imaging techniques in the pancreatobiliary region using radial scanning endoscopic ultrasonography. Dig Endosc 2004;16(Suppl 1):S118-S133.

7. Yamao K, Irisawa A, Inoue H, et al. Standard imaging techniques of endoscopic ultrasound-guided fine-needle aspiration using a curved linear array echoendoscope. Dig Endosc 2007;16(Suppl 1):S180-S205.

8. Polkowski M, Larghi A, Weynand B, et al. Learning, techniques, and complications of endoscopic ultrasound (EUS)-guided sampling in gastroenterology: European Society of Gastrointestinal Endoscopy (ESGE) technical guideline. Endoscopy 2012;44:190206.

9. Bhatia V, Varadarajulu S. Endoscopic ultrasonography-guided tissue acquisition: how to achieve excellence. Dig Endosc 2017;29:417-430.

10. May A, Günter E, Roth F, et al. Accuracy of staging in early oesophageal cancer using high resolution endoscopy and high resolution endosonography: a comparative, prospective, and blinded trial. Gut 2004;53:634-640.

11. Goda K, Tajiri H, Ikegami M, et al. Magnifying endoscopy with narrow band imaging for predicting the invasion depth of superficial esophageal squamous cell carcinoma. Dis Esophagus 2009;22:453-460.

12. Lee MW, Kim GH, I H, et al. Predicting the invasion depth of esophageal squamous cell carcinoma: comparison of endoscopic ultrasonography and magnifying endoscopy. Scand J Gastroenterol 2014;49:853-861.

13. Ohashi S, Segawa K, Okamura S, et al. The utility of endoscopic ultrasonography and endoscopy in the endoscopic mucosal resection of early gastric cancer. Gut 1999;45:599-604.

14. Yanai H, Noguchi T, Mizumachi S, et al. A blind comparison of the effectiveness of endoscopic ultrasonography and endoscopy in staging early gastric cancer. Gut 1999;44:361-365.

15. Choi J, Kim SG, Im JP, Kim JS, Jung HC, Song IS. Comparison of endoscopic ultrasonography and conventional endoscopy for prediction of depth of tumor invasion in early gastric cancer. Endoscopy 2010;42:705-713.

16. Okada K, Fujisaki J, Kasuga A, et al. Endoscopic ultrasonography is valuable for identifying early gastric cancers meeting expanded-indication criteria for endoscopic submucosal dissection. Surg
Endosc 2011;25:841-848.

17. Oyama $\mathrm{T}$, Inoue $\mathrm{H}$, Arima $\mathrm{M}$, et al. Prediction of the invasion depth of superficial squamous cell carcinoma based on microvessel morphology: magnifying endoscopic classification of the Japan Esophageal Society. Esophagus 2017;14:105-112.

18. Gotoda T, Yanagisawa A, Sasako M, et al. Incidence of lymph node metastasis from early gastric cancer: estimation with a large number of cases at two large centers. Gastric Cancer 2000;3:219225.

19. Puli SR, Reddy JB, Bechtold ML, Antillon D, Ibdah JA, Antillon MR. Staging accuracy of esophageal cancer by endoscopic ultrasound: a meta-analysis and systematic review. World J Gastroenterol 2008;14:1479-1490.

20. Thosani N, Singh H, Kapadia A, et al. Diagnostic accuracy of EUS in differentiating mucosal versus submucosal invasion of superficial esophageal cancers: a systematic review and meta-analysis. Gastrointest Endosc 2012;75:242-253.

21. Qumseya BJ, Brown J, Abraham M, et al. Diagnostic performance of EUS in predicting advanced cancer among patients with Barrett's esophagus and high-grade dysplasia/early adenocarcinoma: systematic review and meta-analysis. Gastrointest Endosc 2015;81:865-874.

22. Sun F, Chen T, Han J, Ye P, Hu J. Staging accuracy of endoscopic ultrasound for esophageal cancer after neoadjuvant chemotherapy: a meta-analysis and systematic review. Dis Esophagus 2015;28:757-771.

23. Mocellin S, Pasquali S. Diagnostic accuracy of endoscopic ultrasonography (EUS) for the preoperative locoregional staging of primary gastric cancer. Cochrane Database Syst Rev 2015;(2):CD009944.

24. Puli SR, Bechtold ML, Reddy JB, Choudhary A, Antillon MR, Brugge WR. How good is endoscopic ultrasound in differentiating various T stages of rectal cancer? Meta-analysis and systematic review. Ann Surg Oncol 2009;16:254-265.

25. Dewitt J, Devereaux BM, Lehman GA, Sherman S, Imperiale TF. Comparison of endoscopic ultrasound and computed tomography for the preoperative evaluation of pancreatic cancer: a systematic review. Clin Gastroenterol Hepatol 2006;4:717-725.

26. Legmann P, Vignaux 0, Dousset B, et al. Pancreatic tumors: comparison of dual-phase helical CT and endoscopic sonography. AJR Am J Roentgenol 1998;170:1315-1322.

27. Harinck F, Konings IC, Kluijt I, et al. A multicenter comparative prospective blinded analysis of EUS and MRI for screening of pancreatic cancer in high-risk individuals. Gut 2016;65:15051513.

28. Puli SR, Singh S, Hagedorn CH, Reddy J, Olyaee M. Diagnostic accuracy of EUS for vascular invasion in pancreatic and periampullary cancers: a meta-analysis and systematic review. Gastrointest Endosc 2007;65:788-797.

29. Snady H. EUS criteria for vascular invasion: analyzing the metaanalysis. Gastrointest Endosc 2007;65:798-807.

30. DeWitt J, Devereaux B, Chriswell M, et al. Comparison of endo- 
scopic ultrasonography and multidetector computed tomography for detecting and staging pancreatic cancer. Ann Intern Med 2004;141:753-763.

31. Tellez-Avila FI, Chavez-Tapia NC, López-Arce G, et al. Vascular invasion in pancreatic cancer: predictive values for endoscopic ultrasound and computed tomography imaging. Pancreas 2012;41:636-638.

32. Nawaz H, Fan CY, Kloke J, et al. Performance characteristics of endoscopic ultrasound in the staging of pancreatic cancer: a meta-analysis. JOP 2013;14:484-497.

33. Soriano A, Castells A, Ayuso C, et al. Preoperative staging and tumor resectability assessment of pancreatic cancer: prospective study comparing endoscopic ultrasonography, helical computed tomography, magnetic resonance imaging, and angiography. Am J Gastroenterol 2004;99:492-501.

34. Tse F, Liu L, Barkun AN, Armstrong D, Moayyedi P. EUS: a metaanalysis of test performance in suspected choledocholithiasis. Gastrointest Endosc 2008;67:235-244.

35. Garrow D, Miller S, Sinha D, et al. Endoscopic ultrasound: a meta-analysis of test performance in suspected biliary obstruction. Clin Gastroenterol Hepatol 2007;5:616-623.

36. Sugiyama M, Atomi Y. Endoscopic ultrasonography for diagnosing choledocholithiasis: a prospective comparative study with ultrasonography and computed tomography. Gastrointest Endosc 1997;45:143-146.

37. Giljaca V, Gurusamy KS, Takwoingi Y, et al. Endoscopic ultrasound versus magnetic resonance cholangiopancreatography for common bile duct stones. Cochrane Database Syst Rev 2015;(2):CD011549.

38. Romagnuolo J, Bardou M, Rahme E, Joseph L, Reinhold C, Barkun AN. Magnetic resonance cholangiopancreatography: a meta-analysis of test performance in suspected biliary disease. Ann Intern Med 2003;139:547-557.

39. Verma D, Kapadia A, Eisen GM, Adler DG. EUS vs MRCP for detection of choledocholithiasis. Gastrointest Endosc 2006;64:248254.

40. Zidi SH, Prat F, Le Guen 0, et al. Use of magnetic resonance cholangiography in the diagnosis of choledocholithiasis: prospective comparison with a reference imaging method. Gut 1999;44:118122.

41. Sugiyama M, Atomi Y, Hachiya J. Magnetic resonance cholangiography using half-Fourier acquisition for diagnosing choledocholithiasis. Am J Gastroenterol 1998;93:1886-1890.

42. Boraschi P, Neri E, Braccini G, et al. Choledocolithiasis: diagnostic accuracy of MR cholangiopancreatography: three-year experience. Magn Reson Imaging 1999;17:1245-1253.

43. ASGE Standards of Practice Committee, Maple JT, Ben-Menachem $\mathrm{T}$, et al. The role of endoscopy in the evaluation of suspected choledocholithiasis. Gastrointest Endosc 2010;71:1-9.

44. Lachter J, Rubin A, Shiller M, et al. Linear EUS for bile duct stones. Gastrointest Endosc 2000;51:51-54.

45. Conwell DL, Zuccaro G, Purich E, et al. Comparison of endoscopic ultrasound chronic pancreatitis criteria to the endoscopic secretinstimulated pancreatic function test. Dig Dis Sci 2007;52:12061210.

46. Catalano MF, Sahai A, Levy M, et al. EUS-based criteria for the diagnosis of chronic pancreatitis: the Rosemont classification. Gastrointest Endosc 2009;69:1251-1261.

47. Stevens T, Lopez R, Adler DG, et al. Multicenter comparison of the interobserver agreement of standard EUS scoring and Rosemont classification scoring for diagnosis of chronic pancreatitis. Gastrointest Endosc 2010;71:519-526.

48. Del Pozo D, Poves E, Tabernero S, et al. Conventional versus Rosemont endoscopic ultrasound criteria for chronic pancreatitis: interobserver agreement in same day back-to-back procedures. Pancreatology 2012;12:284-287.

49. Petrone MC, Terracciano F, Perri F, et al. Pancreatic abnormalities detected by endoscopic ultrasound (EUS) in patients without clinical signs of pancreatic disease: any difference between standard and Rosemont classification scoring? Pancreatology 2014;14:227-230.

50. D'Souza SL, Anderson MA, Korsnes SJ, et al. EUS diagnostic criteria for chronic pancreatitis: a comparison of conventional versus rosemont criteria. Dig Dis Sci 2015;60:3782-3787.

51. Song MH, Lee SK, Kim MH, et al. EUS in the evaluation of pancreatic cystic lesions. Gastrointest Endosc 2003;57:891-896.

52. Koito K, Namieno T, Nagakawa T, Shyonai T, Hirokawa N, Morita K. Solitary cystic tumor of the pancreas: EUS-pathologic correlation. Gastrointest Endosc 1997;45:268-276.

53. O'Toole D, Palazzo L, Hammel P, et al. Macrocystic pancreatic cystadenoma: the role of EUS and cyst fluid analysis in distinguishing mucinous and serous lesions. Gastrointest Endosc 2004;59:823-829.

54. Brugge WR, Lewandrowski K, Lee-Lewandrowski E, et al. Diagnosis of pancreatic cystic neoplasms: a report of the cooperative pancreatic cyst study. Gastroenterology 2004;126:1330-1336.

55. Kim KW, Park SH, Pyo J, et al. Imaging features to distinguish malignant and benign branch-duct type intraductal papillary mucinous neoplasms of the pancreas: a meta-analysis. Ann Surg 2014;259:72-81.

56. Tanaka M, Fernández-Del Castillo C, Kamisawa T, et al. Revisions of international consensus Fukuoka guidelines for the management of IPMN of the pancreas. Pancreatology 2017;17:738-753.

57. Fernández-del Castillo C, Targarona J, Thayer SP, Rattner DW, Brugge WR, Warshaw AL. Incidental pancreatic cysts: clinicopathologic characteristics and comparison with symptomatic patients. Arch Surg 2003;138:427-423.

58. ASGE Standards of Practice Committee, Muthusamy VR, Chandrasekhara $\mathrm{V}$, et al. The role of endoscopy in the diagnosis and treatment of cystic pancreatic neoplasms. Gastrointest Endosc 2016;84:1-9.

59. Thornton GD, McPhail MJ, Nayagam S, Hewitt MJ, Vlavianos P, Monahan KJ. Endoscopic ultrasound guided fine needle aspiration for the diagnosis of pancreatic cystic neoplasms: a meta- 
analysis. Pancreatology 2013;13:48-57.

60. ASGE Standards of Practice Committee, Gan SI, Rajan E, et al. Role of EUS. Gastrointest Endosc 2007;66:425-434.

61. Micames CG, McCrory DC, Pavey DA, Jowell PS, Gress FG. Endoscopic ultrasound-guided fine-needle aspiration for non-small cell lung cancer staging: a systematic review and metaanalysis. Chest 2007;131:539-548.

62. Puli SR, Bechtold ML, Buxbaum JL, Eloubeidi MA. How good is endoscopic ultrasound-guided fine-needle aspiration in diagnosing the correct etiology for a solid pancreatic mass? A metaanalysis and systematic review. Pancreas 2013;42:20-26.

63. Bang JY, Magee SH, Ramesh J, Trevino JM, Varadarajulu S. Randomized trial comparing fanning with standard technique for endoscopic ultrasound-guided fine-needle aspiration of solid pancreatic mass lesions. Endoscopy 2013;45:445-450.

64. Wallace MB, Kennedy T, Durkalski V, et al. Randomized controlled trial of EUS-guided fine needle aspiration techniques for the detection of malignant lymphadenopathy. Gastrointest Endosc 2001;54:441-447.

65. Puri R, Vilmann P, Săftoiu A, et al. Randomized controlled trial of endoscopic ultrasound-guided fine-needle sampling with or without suction for better cytological diagnosis. Scand J Gastroenterol 2009;44:499-504.

66. Lee JK, Choi JH, Lee KH, et al. A prospective, comparative trial to optimize sampling techniques in EUS-guided FNA of solid pancreatic masses. Gastrointest Endosc 2013;77:745-751.

67. Nakai $\mathrm{Y}$, Isayama $\mathrm{H}$, Chang $\mathrm{KJ}$, et al. Slow pull versus suction in endoscopic ultrasound-guided fine-needle aspiration of pancreatic solid masses. Dig Dis Sci 2014;59:1578-1585.

68. Attam R, Arain MA, Bloechl SJ, et al. "Wet suction technique (WEST)": a novel way to enhance the quality of EUS-FNA aspirate. Results of a prospective, single-blind, randomized, controlled trial using a 22-gauge needle for EUS-FNA of solid lesions. Gastrointest Endosc 2015;81:1401-1407.

69. Erickson RA, Sayage-Rabie L, Beissner RS. Factors predicting the number of EUS-guided fine-needle passes for diagnosis of pancreatic malignancies. Gastrointest Endosc 2000;51:184-190.

70. Klapman JB, Logrono R, Dye CE, Waxman I. Clinical impact of on-site cytopathology interpretation on endoscopic ultrasoundguided fine needle aspiration. Am J Gastroenterol 2003;98:12891294.

71. Kulesza P, Eltoum IA. Endoscopic ultrasound-guided fine-needle aspiration: sampling, pitfalls, and quality management. Clin Gastroenterol Hepatol 2007;5:1248-1254.

72. Pellisé Urquiza M, Fernández-Esparrach G, Solé M, et al. Endoscopic ultrasound-guided fine needle aspiration: predictive factors of accurate diagnosis and cost-minimization analysis of on-site pathologist. Gastroenterol Hepatol 2007;30:319-324.

73. Turner BG, Cizginer S, Agarwal D, Yang J, Pitman MB, Brugge WR. Diagnosis of pancreatic neoplasia with EUS and FNA: a report of accuracy. Gastrointest Endosc 2010;71:91-98.

74. LeBlanc JK, Ciaccia D, Al-Assi MT, et al. Optimal number of EUS- guided fine needle passes needed to obtain a correct diagnosis. Gastrointest Endosc 2004;59:475-481.

75. Affolter KE, Schmidt RL, Matynia AP, Adler DG, Factor RE. Needle size has only a limited effect on outcomes in EUS-guided fine needle aspiration: a systematic review and meta-analysis. Dig Dis Sci 2013;58:1026-1034.

76. Madhoun MF, Wani SB, Rastogi A, et al. The diagnostic accuracy of 22-gauge and 25-gauge needles in endoscopic ultrasoundguided fine needle aspiration of solid pancreatic lesions: a metaanalysis. Endoscopy 2013;45:86-92.

77. Wee E, Lakhtakia S, Gupta R, et al. Endoscopic ultrasound guided fine-needle aspiration of lymph nodes and solid masses: factors influencing the cellularity and adequacy of the aspirate. J Clin Gastroenterol 2012;46:487-493.

78. Rong L, Kida M, Yamauchi H, et al. Factors affecting the diagnostic accuracy of endoscopic ultrasonography-guided fine-needle aspiration (EUS-FNA) for upper gastrointestinal submucosal or extraluminal solid mass lesions. Dig Endosc 2012;24:358-363.

79. Ang TL, Kwek AB, Seo DW, et al. A prospective randomized study of the difference in diagnostic yield between endoscopic ultrasound-guided fine-needle aspiration (EUSFNA) needles with and without a side port in pancreatic masses. Endosc Int Open 2015;3:E329-E333.

80. Ishiwatari H, Hayashi T, Kawakami H, et al. Randomized trial comparing a side-port needle and standard needle for EUS-guided histology of pancreatic lesions. Gastrointest Endosc 2016;84:670678.

81. Iglesias-Garcia J, Poley JW, Larghi A, et al. Feasibility and yield of a new EUS histology needle: results from a multicenter, pooled, cohort study. Gastrointest Endosc 2011;73:1189-1196.

82. DeWitt J, Cho CM, Lin J, et al. Comparison of EUS-guided tissue acquisition using two different 19-gauge core biopsy needles: a multicenter, prospective, randomized, and blinded study. Endosc Int Open 2015;3:E471-E478.

83. Mitri RD, Rimbaş M, Attili F, et al. Performance of a new needle for endoscopic ultrasound-guided fine-needle biopsy in patients with pancreatic solid lesions: a retrospective multicenter study. Endosc Ultrasound. Epub 2017 Aug 24. https://doi.org/10.4103/ eus.eus_33_17.

84. Jovani M, Abidi WM, Lee LS. Novel fork-tip needles versus standard needles for EUS-guided tissue acquisition from solid masses of the upper GI tract: a matched cohort study. Scand J Gastroenterol 2017;52:784-787.

85. Mukai S, Itoi T, Katanuma A, Irisawa A. An animal experimental study to assess the core tissue acquisition ability of endoscopic ultrasound-guided histology needles. Endosc Ultrasound 2018;7:263-269.

86. Khan MA, Grimm IS, Ali B, et al. A meta-analysis of endoscopic ultrasound-fine-needle aspiration compared to endoscopic ultrasound-fine-needle biopsy: diagnostic yield and the value of onsite cytopathological assessment. Endosc Int Open 2017;5:E363E375. 
87. Bang JY, Hawes R, Varadarajulu S. A meta-analysis comparing ProCore and standard fine-needle aspiration needles for endoscopic ultrasound-guided tissue acquisition. Endoscopy 2016;48:339-349.

88. Kim GH, Cho YK, Kim EY, et al. Comparison of 22-gauge aspiration needle with 22-gauge biopsy needle in endoscopic ultrasonography-guided subepithelial tumor sampling. Scand J Gastroenterol 2014;49:347-354.

89. Hedenström P, Marschall HU, Nilsson B, et al. High clinical impact and diagnostic accuracy of EUS-guided biopsy sampling of subepithelial lesions: a prospective, comparative study. Surg Endosc 2018;32:1304-1313.

90. El Chafic AH, Loren D, Siddiqui A, Mounzer R, Cosgrove N, Kowalski T. Comparison of FNA and fine-needle biopsy for EUSguided sampling of suspected GI stromal tumors. Gastrointest Endosc 2017;86:510-515.

91. ASGE Standards of Practice Committee, Early DS, Acosta RD, et al. Adverse events associated with EUS and EUS with FNA. Gastrointest Endosc 2013;77:839-843.

92. Wang KX, Ben QW, Jin ZD, et al. Assessment of morbidity and mortality associated with EUS-guided FNA: a systematic review. Gastrointest Endosc 2011;73:283-290.

93. Zhu H, Jiang F, Zhu J, Du Y, Jin Z, Li Z. Assessment of morbidity and mortality associated with endoscopic ultrasound-guided fine-needle aspiration for pancreatic cystic lesions: a systematic review and meta-analysis. Dig Endosc 2017;29:667-675.

94. Seicean A, Mosteanu 0, Seicean R. Maximizing the endosonography: the role of contrast harmonics, elastography and confocal endomicroscopy. World J Gastroenterol 2017;23:25-41.

95. Imazu H, Kanazawa K, Mori N, et al. Novel quantitative perfusion analysis with contrast-enhanced harmonic EUS for differentiation of autoimmune pancreatitis from pancreatic carcinoma. Scand J
Gastroenterol 2012;47:853-860.

96. Gong TT, Hu DM, Zhu Q. Contrast-enhanced EUS for differential diagnosis of pancreatic mass lesions: a meta-analysis. Gastrointest Endosc 2012;76:301-309.

97. Kamata K, Kitano M, Omoto S, et al. Contrast-enhanced harmonic endoscopic ultrasonography for differential diagnosis of pancreatic cysts. Endoscopy 2016;48:35-41.

98. Sakamoto H, Kitano M, Matsui S, et al. Estimation of malignant potential of GI stromal tumors by contrast-enhanced harmonic EUS (with videos). Gastrointest Endosc 2011;73:227-237.

99. Imazu H, Mori N, Kanazawa K, et al. Contrast-enhanced harmonic endoscopic ultrasonography in the differential diagnosis of gallbladder wall thickening. Dig Dis Sci 2014;59:1909-1916.

100. Miyata T, Kitano M, Omoto S, et al. Contrast-enhanced harmonic endoscopic ultrasonography for assessment of lymph node metastases in pancreatobiliary carcinoma. World J Gastroenterol 2016;22:3381-3391.

101. Ying L, Lin X, Xie ZL, Hu YP, Tang KF, Shi KQ. Clinical utility of endoscopic ultrasound elastography for identification of malignant pancreatic masses: a meta-analysis. J Gastroenterol Hepatol 2013;28:1434-1443.

102. Larsen MH, Fristrup C, Hansen TP, Hovendal CP, Mortensen MB. Endoscopic ultrasound, endoscopic sonoelastography, and strain ratio evaluation of lymph nodes with histology as gold standard. Endoscopy 2012;44:759-766.

103. Itoh Y, Itoh A, Kawashima H, et al. Quantitative analysis of diagnosing pancreatic fibrosis using EUS-elastography (comparison with surgical specimens). J Gastroenterol 2014;49:1183-1192.

104. Xu W, Shi J, Zeng X, et al. EUS elastography for the differentiation of benign and malignant lymph nodes: a meta-analysis. Gastrointest Endosc 2011;74:1001-1009. 